\title{
ANÁLISE COMPARATIVA DO CONSUMO DE ÁGUA DE DOIS BAIRROS DA CIDADE DE SÃO CARLOS (SP)
}

\author{
Gabriel Ayabe Ninomiya ${ }^{1}$
}

\section{Erich Kellner ${ }^{2}$}

\section{Jorge Akutsu ${ }^{3}$}

Resumo: A implantação ou ampliação de sistemas de abastecimento de água apresenta, como premissa básica, a determinação da vazão de demanda. Essa, por sua vez requer, dentre outros parâmetros, a avaliação do consumo percapita efetivo de água, o qual pode variar segundo características socioeconômicas, culturais e ambientais. Como o consumo de água é influenciado pelas condições da infraestrutura sanitária, existência de micromedição, poder aquisitivo do domicílio atendido, questões climáticas, entre outros, a determinação das vazões percapitas para setores de abastecimento de uma cidade, por exemplo, podem permitir um melhor planejamento da expansão dos sistemas de abastecimento de água e análises mais precisas das eventuais necessidades de melhoria e expansão da infraestrutura de abastecimento de água. O objetivo geral do presente trabalho foi o de comparar o consumo médio efetivo de água potável dos bairros Douradinho e Parque Faber II, ambos localizados na cidade de São Carlos, analisar esse consumo sob a ótica socioeconômica domiciliar, além de estimar os coeficientes do dia de

\footnotetext{
1 Aluno do curso de graduação em Engenharia Civil (DECiv) da Universidade Federal de São Carlos (UFSCar). E-mail:Gabriel.ayabe@gmail.com

2 Engenheiro Civil (UFSCar). Mestre e Doutor em Hidráulica e Saneamento (EESC/USP). Professor do Departamento de Engenharia Civil (DECiv) da Universidade Federal de São Carlos (UFSCar). E-mail: erich.kellner@ufscar.br

${ }^{3}$ Engenheiro Civil (EESC/USP). Mestre e Doutor em Hidráulica e Saneamento (EESC/USP). Professor do Departamento de Engenharia Civil (DECiv) da Universidade Federal de São Carlos (UFSCar). E-mail: akutsu@ufscar.br
} 

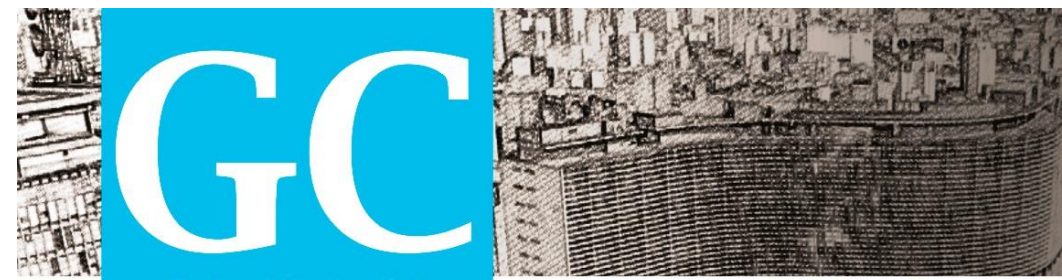

Revista Nacional de

Gerenciamento de Cidades

maior consumo $\left(\mathrm{K}_{1}\right)$ para cada um dos loteamentos. Para o loteamento Faber II, cujo rendimento domiciliar médio mensal era de $\mathrm{R} \$ 9.448,90$, o consumo médio percapita efetivo foi de 321,3 L/hab.dia, enquanto que para o loteamento Douradinho, cujo rendimento domiciliar médio mensal era de $\mathrm{R} \$ 2.206,75$, o consumo médio percapita efetivo foi de 138,3 L/hab.dia. Os coeficientes do dia de maior consumo $\left(\mathrm{K}_{1}\right)$ para os birros Faber II e Douradinho resultaram em, respectivamente, 1,64 e 1,26.

Palavras-chave: Sistema de Abastecimento de Água. Consumo percapita Efetivo de Água. Previsão de Demanda.

\section{INTRODUÇÃO}

A implantação ou ampliação de sistemas de abastecimento de água apresenta, como premissa básica, a determinação da vazão de demanda. Essa, por sua vez requer, dentre outros parâmetros, a avaliação do consumo de água percapita.

O consumo per capita é o volume de água diário, requerido por indivíduo, usualmente expresso em L/hab.dia. Esse valor é adotado, nos projetos de sistemas de abastecimento de água, para satisfazer aos consumos doméstico, comercial, industrial e público, bem como às perdas físicas. (ABNT, 1992).

Segundo o SNIS - Sistema Nacional de Informações sobre o Saneamento (SNIS, 2012) o consumo médio de água no Brasil, envolvendo os setores comercial, residencial, público e industrial, está na faixa de 162 litros por habitante/dia, sendo que a média dos últimos três anos foi de 152,6 L/hab.dia. No entanto, há grandes variações nesse consumo: enquanto o Estado de Alagoas apresentou média de 96,0 L/hab.dia, o menor consumo médio do país, o Estado do Rio de Janeiro obteve média de consumo de 237,8 L/hab.dia.

A Figura 1 ilustra o consumo médio percapita de água nos estados do Brasil e no Distrito Federal. 

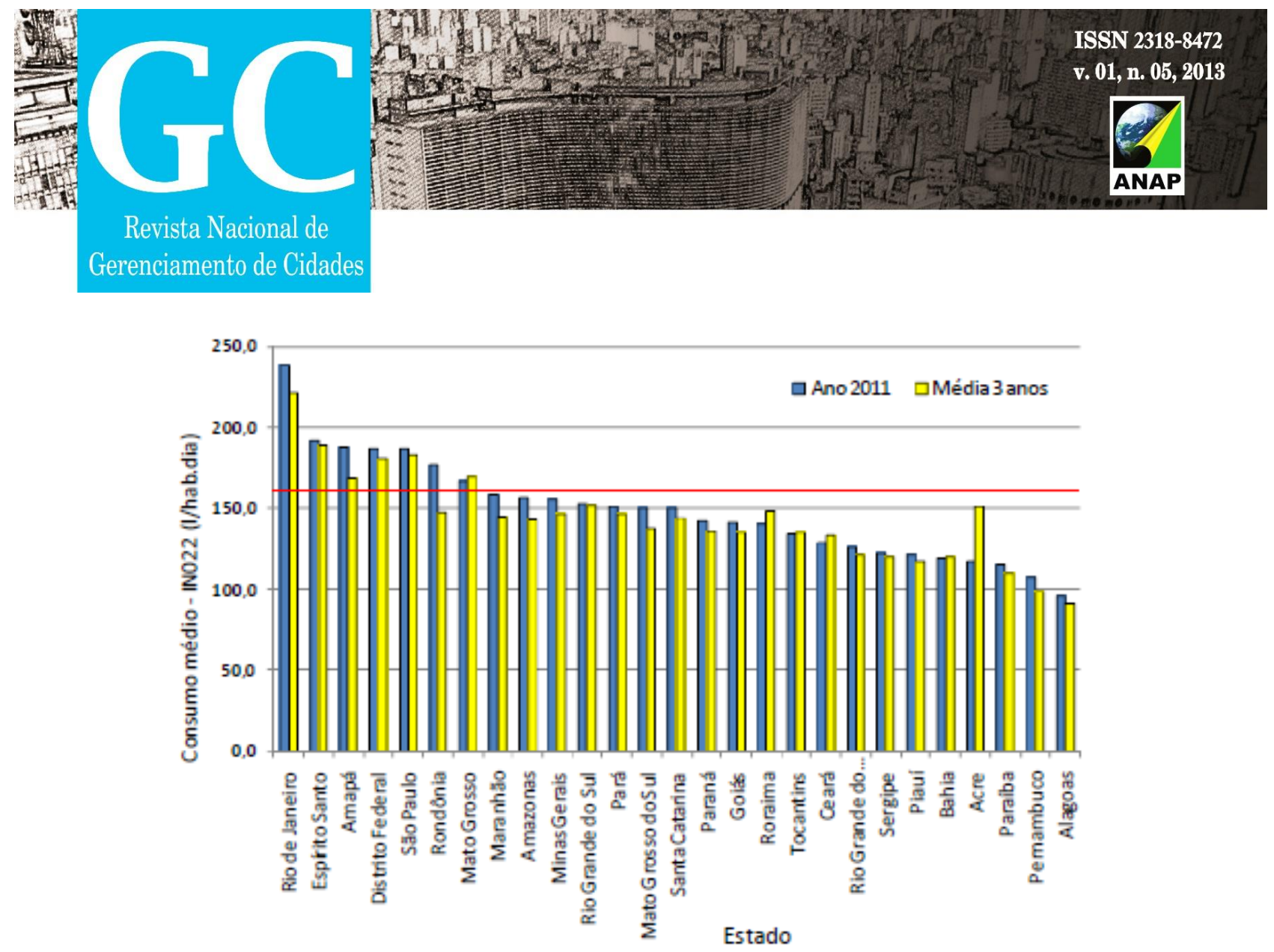

Figura 1: Consumo médio percapita de água nos Estados e Distrito Federal

Fonte: SNIS (2012).

Como o consumo de água é influenciado pelas condições da infraestrutura sanitária, existência de micromedição, poder aquisitivo, questões climáticas, a determinação das vazões percapitas para setores de uma cidade, por exemplo, permitem o melhor planejamento da expansão urbana e análise das eventuais melhorias da infraestrutura sanitária.

O objetivo geral do trabalho foi o de avaliar o consumo médio percapita efetivo de água potável dos bairros Douradinho e Parque Faber II, ambos localizados na cidade de São Carlos, com a renda média mensal domiciliar de cada loteamento considerado.

\section{REVISÃO BIBLIOGRÁFICA}

Para o gerenciamento e planejamento dos sistemas de abastecimento de água, a estimativa do consumo de água é um dos fatores de suma importância.

Essa importância é realçada se se considerar que o dimensionamento das tubulações, estruturas, equipamentos é função das vazões de água, as quais dependem 
Revista Nacional de

Gerenciamento de Cidades

do consumo médio por habitante, além de outros fatores característicos da área de estudo (SNIS, 2012).

Tsutiya (2006) menciona que, de maneira geral, o consumo de água de um determinado setor de abastecimento pode ser determinado por um dos métodos: leitura dos hidrômetros, leitura do macromedidor instalado na saída do reservatório que abastece o setor, ou por valores adotados a partir de observações de setores semelhantes, sendo este último método empregado quando não existem quaisquer outras medições em relação ao setor analisado.

\subsection{Consumo Médio percapita de água}

O consumo médio per capita de água é definido pelo SNIS (2012), como o volume de água consumido, excluído o volume de água exportado, dividido pela população atendida com abastecimento de água, ou seja, é a média diária, por indivíduo, dos volumes utilizados para satisfazer os consumos domésticos, comercial, público e industrial.

Tsutiya (2006) menciona que o consumo médio percapita $(q)$ incorpora as perdas de água do sistema de abastecimento (I).

As perdas de água no sistema de abastecimento, que se referem ao índice de perdas na distribuição, estão relacionadas aos volumes de água disponibilizados para distribuição e os volumes de água efetivamente consumidos e registrados pelos micromedidores, instalados nas economias (SNIS, 2012).

Dessa maneira, tem-se o consumo médio percapita $(q)$ e o consumo médio percapita efetivo $\left(q_{e}\right)$, conforme expresso pela Equação (1).

Equação (1)

onde $q$ é o consumo médio percapita de água (L/hab.dia); $q_{e}$ é o consumo médio percapita efetivo de água (L/hab.dia), e I é o índice de perda física de água no sistema de distribuição (decimal).

Os índices de perdas estão diretamente associados à qualidade da infraestrutura e da gestão dos sistemas. Para explicar a existência de perdas de água em patamares 

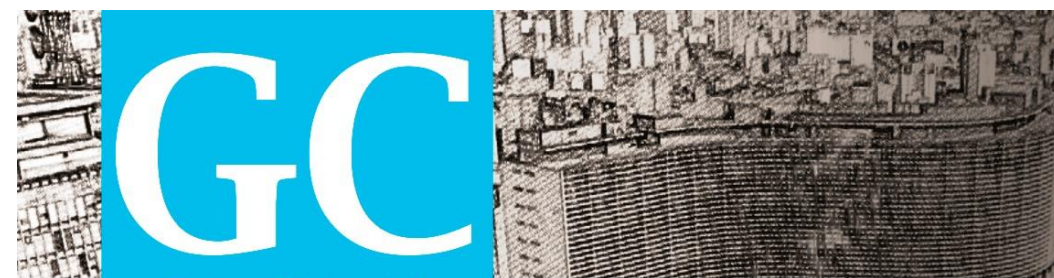

Revista Nacional de

Gerenciamento de Cidades

acima do "aceitável", o SNIS (2012) sugere que algumas hipóteses podem ser levantadas, tais como: falhas na detecção de vazamentos; redes de distribuição funcionando com pressões muito altas; problemas na qualidade da operação dos sistemas; aferição/calibração dos hidrômetros; ausência de programa de monitoramento de perdas; dentre outras hipóteses.

Para o município de São Carlos, que tem o sistema público de abastecimento de água e de esgotamento sanitário operado pelo Serviço Autônomo de Água e Esgoto SAAE, o SNIS $(2008,2009,2010,2011$ e 2012) reportou os valores de consumo médio percapita de água e índices de perda na rede de distribuição conforme apresentados na Tabela 1.

Tabela 1: Consumo médio percapita de água e Índice de perda na rede de distribuição de água para a cidade de São Carlos, segundo área de cobertura do SAAE-São Carlos

\begin{tabular}{c|c|c|c}
\hline Ano & $\begin{array}{c}\text { Consumo Médio } \\
\text { Percapita } \\
\text { (L/hab/dia) }\end{array}$ & $\begin{array}{c}\text { Índice de Perda } \\
\text { na Rede de } \\
\text { Distribuição } \\
(\%)\end{array}$ & Fonte \\
\hline 2011 & 188,8 & 46,0 & SNIS (2012) \\
\hline 2010 & 189,1 & 48,9 & SNIS (2011) \\
\hline 2009 & 174,4 & 54,1 & SNIS (2010) \\
\hline 2008 & 178,3 & 52,4 & SNIS (2009) \\
\hline 2007 & 177,9 & 50,8 & SNIS (2008) \\
\hline
\end{tabular}

Tsutiya (2006) menciona que é comum fixar um índice de perda de $20 \%$, e não utilizar valores reais, que geralmente são bem maiores.

\subsection{Variações Sazonais no Consumo de Água}

Nos sistemas de abastecimento de água, a quantidade de água consumida varia continuamente em função do tempo, das condições climáticas, hábitos da população, etc. Segundo Tsutiya (2006), o consumo doméstico apresenta uma grande variação, enquanto que para o consumo industrial a vazão é menor. 

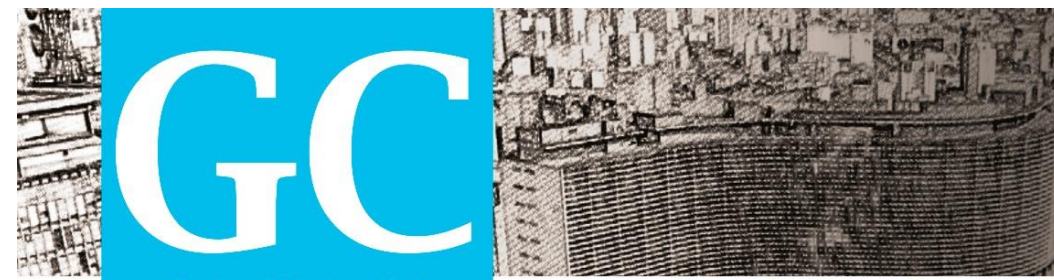

Revista Nacional de

Gerenciamento de Cidades

De maneira geral, o consumo de água de uma determinada região, pode apresentar variações anuais, mensais diárias, horárias e instantâneas.

A variação anual no consumo médio percapita de água tende a crescer com o decorrer do tempo, devido a melhoria dos hábitos higiênicos da população e do desenvolvimento industrial (TSUTIYA, 2006). De certa maneira a Tabela 1 mostra 0 crescimento do consumo médio percapita da cidade de São Carlos entre os períodos de 2007 e 2011.

Ainda segundo Tsutiya (2006) a variação das vazões médias percapitas ao longo dos meses decorre de no verão o consumo superar o consumo médio, enquanto que no inverno, o consumo é menor.

Conhecido como $\mathrm{K}_{1}$, o coeficiente do dia de maior consumo é a razão entre o maior consumo diário analisado ao longo de um ano e o consumo médio diário no mesmo período de tempo, levando-se em conta sempre as mesmas ligações.

Para o cálculo desse coeficiente (que é sempre maior que um), devem ser ignorados os dias em que ocorram anormalidades ou excepcionalidades devido ao consumo de água. Além disso, é recomendada a consideração de no mínimo cinco anos de observação, utilizando-se das médias dos coeficientes determinados (TSUTIYA, 2006).

A ANA - Agência Nacional de Águas (ANA, 2008), assim como vários autores, recomendam, para a execução de projetos, que o valor do dia de maior consumo $\left(\mathrm{K}_{1}\right)$ seja de 1,20 na falta de melhor informação. Por outro lado, esse coeficiente pode ser calculado pela aplicação da Equação (03).

$\mathrm{K}_{1}$

(Equação 03)

O consumo diário geralmente é maior ou menor que o consumo médio diário anual, sendo que o consumo é maior no verão e menor no inverno. Da mesma maneira, a variação horária, reflete a variação do consumo com as horas do dia, sendo que, geralmente, o consumo aumenta entre 10h e 12h (TSUTIYA, 2006).

$\mathrm{O}$ coeficiente da hora de maior consumo, conhecido como coeficiente $\mathrm{K}_{2}$, é a relação entre a maior vazão de água ocorrida em um determinado horário do dia e a vazão média horária desse mesmo dia. Assim como no coeficiente $\mathrm{K}_{1}$, as anormalidades 
Revista Nacional de

Gerenciamento de Cidades

ou excepcionalidades ocorridas devido ao consumo de água devem ser excluídas do cálculo. A Equação (04) representa a formulação para o cálculo do coeficiente $K_{2}$.

A extinta NB-587 (ABNT, 1977) recomendava, para a execução de projetos, valores de $\mathrm{K}_{2}$ próximos a 1,5. Embora essa Norma Técnica tenha sido substituída pela NBR 12.211/1992 (ABNT, 1992), a qual não faz menção a possíveis valores para $K_{2}$, é prática usual entre projetistas, quando da ausência de dados mais precisos, usar o valor proposto pela extinta NB-587/77.

As variações instantâneas são características de sistemas de abastecimento que não possuem reservatório domiciliar, estando os aparelhos hidráulicos da residência ligados diretamente à rede pública de distribuição de água.

\section{MATERIAL E MÉTODOS}

Nesta seção foram apresentados os matérias e métodos empregados na condução da pesquisa desenvolvida, bem como a descrição dos bairros localizados.

\section{1. Áreas de Intervenção}

No presente trabalho foram estudados os consumos de água nos bairros Douradinho e Faber II, ambos pertencentes a cidade de São Carlos. A

Figura 2 indica a localização dos dois bairros estudados em relação a malha urbana. 


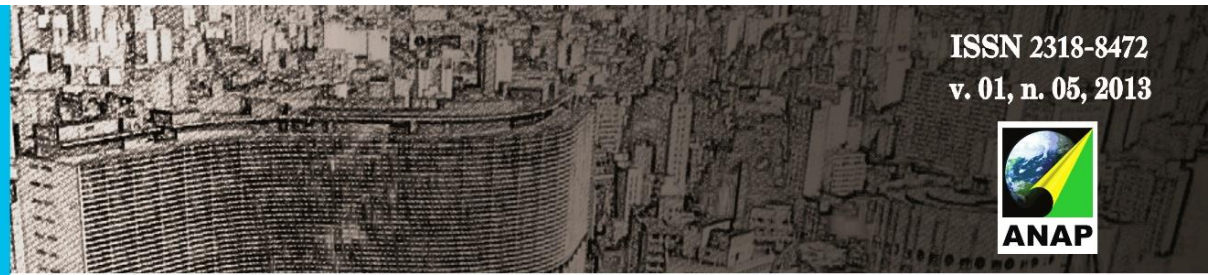

Revista Nacional de

Gerenciamento de Cidades

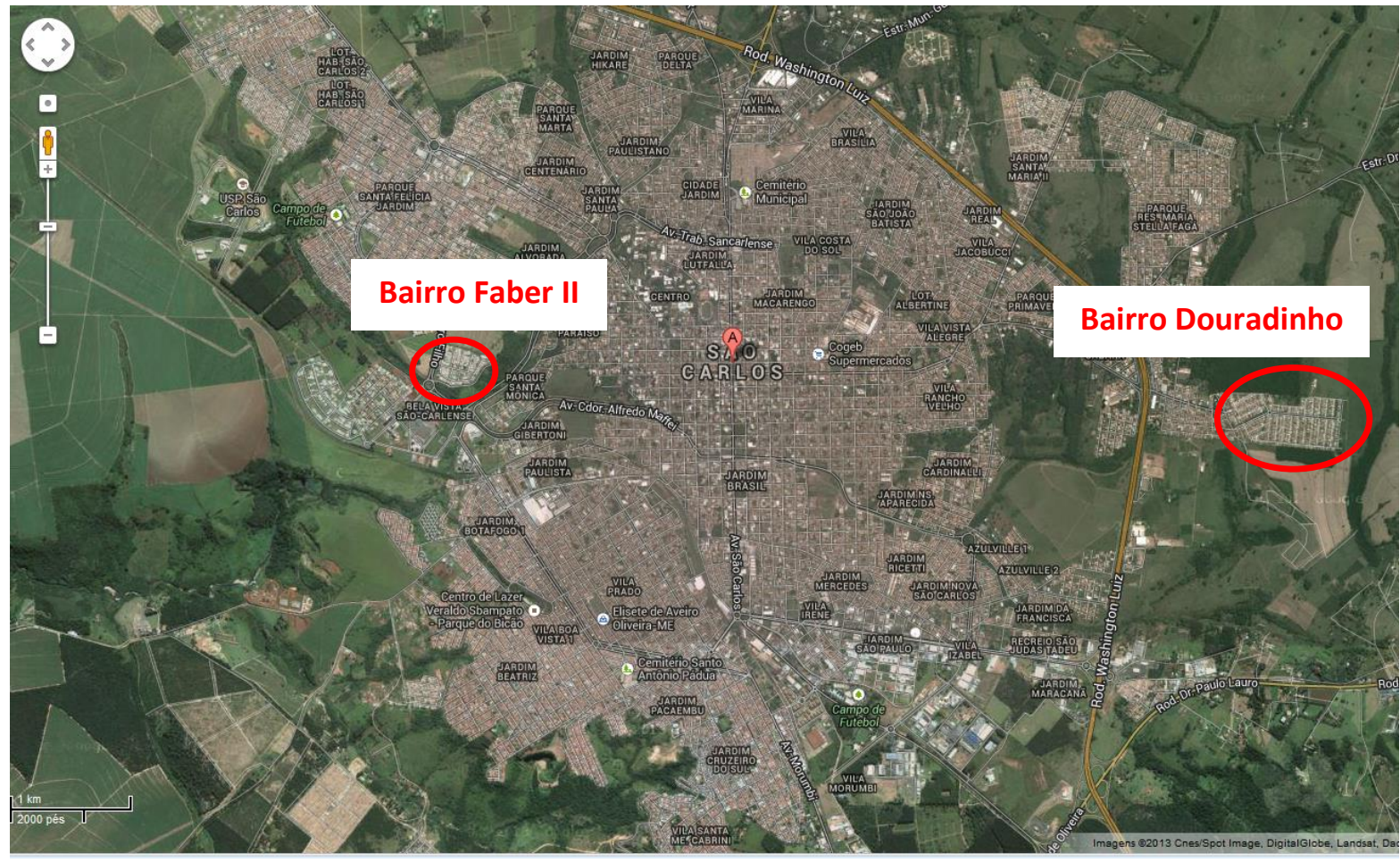

Figura 2: Localização dos bairros Douradinho e Faber II em relação a malha urbana de São Carlos. Fonte: GoogleMaps (2013)

O loteamento denominado Parque Faber II, aprovado em 16 de setembro de 2003 pelo Decreto Municipal n. 133 (SÃO CARLOS, 2003) é constituído por 158 lotes, distribuídos em 11 quadras, totalizando 162.158,99 m², está localizado na região leste do município. Segundo o Plano Diretor do Município de São Carlos (SÃO CARLOS, 2005), o empreendimento está inserido na região denominada Zona 1, de ocupação induzida.

O loteamento denominado Parque Douradinho é constituído por 1297 lotes, distribuídos em 33 quadras, totalizando 431.299,45 m², está localizado na região oeste do município. Segundo o Plano Diretor do Município de São Carlos (SÃO CARLOS, 2005), o empreendimento está inserido na região denominada Zona 3B, de ocupação controlada.

Ambos os bairros são caracterizados por serem regiões residenciais unifamiliares, podendo-se considerar, então, que cada domicílio possui uma única ligação de água.

\subsection{Material}



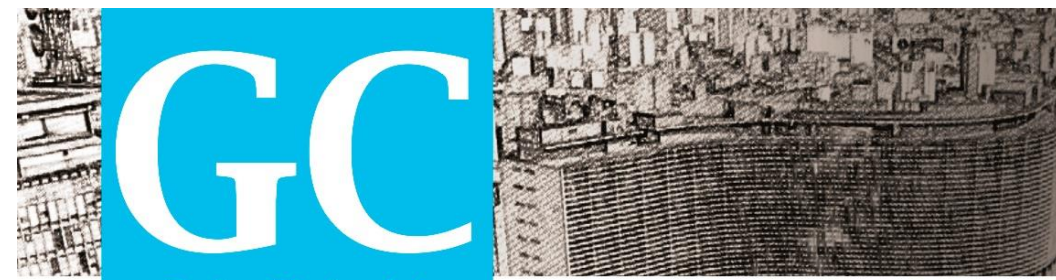

Revista Nacional de

Gerenciamento de Cidades

Para a realização deste trabalho foram necessários:

- Planilha de consumo mensal de água, e número de ligações ativas, distribuído por quadra, para cada um dos dois loteamentos analisados, referentes ao período de janeiro de 2005 até outubro de 2012. Esses dados foram fornecidos pelo Serviço Autônomo de Água e Esgoto de São Carlos - SAAE São Carlos.

- Projetos dos sistemas de abastecimento de água dos dois empreendimentos analisados, fornecidos pelo SAAE São Carlos, em arquivo digital no formato DWG.

\subsection{Método}

A partir dos dados mensais de consumo de água, os quais se referem aos consumos médios efetivos, já que foram a partir das leituras dos hidrômetros, e referentes aos bairros analisados, calculou-se o consumo de água mensal por ligação ativa.

Para o período de 01/01/2005 a 31/10/2012 foi analisado o consumo médio de água, bem como o consumo máximo, sendo obtidos os valores do dia de maior consumo para ambos os empreendimentos. Os índices do dia de maior consumo $\left(\mathrm{K}_{1}\right)$ foram determinados aplicando-se a Equação (03).

Nesse caso, para cada ano, foi calculado o consumo médio e verificado o consumo máximo no ano, sendo determinado, para cada ano, o coeficiente do dia de maior consumo, conforme estabelecido pela NBR 12.211/1992 (ABNT, 1992).

A partir dos dados censitários de 2010 IBGE (2011), determinaram-se os setores que abrangiam os loteamentos analisados. A partir dessa identificação, determinaram-se as áreas dos setores e as áreas realmente ocupadas e inseridas nos setores.

Relacionou-se então a população recenseada pelo IBGE (2011) com as áreas realmente ocupadas, obtendo-se então as densidades populacionais. Ao multiplicar as densidades pelas áreas ocupadas pelos empreendimentos, obteve-se o número de habitantes possivelmente existente nos empreendimentos analisados para o ano de 2010, cujos dados foram obtidos de IBGE (2011). De maneira análoga, obteve-se a renda média domiciliar mensal para cada loteamento, ponderando-se a população recenseada de cada 
Revista Nacional de

Gerenciamento de Cidades

setor com a população possivelmente existente e o total do rendimento nominal mensal dos domicílios particulares, conforme disponibilizado pelo IBGE (2011).

Considerando o índice de perda (I) na distribuição de $20 \%$, conforme sugerido por Tsutiya (2006), estimou-se as vazões médias percapitas por ligação $\left(q_{\mathrm{e}}\right)$, a partir da aplicação da Equação (01).

\section{RESULTADOS E DISCUSSÃO}

Inicialmente avaliou-se a variação do consumo efetivo de água por ligação para cada um dos loteamentos considerados, no período de janeiro de 2005 a outubro de 2012.

Analisando a Figura 7 é possível observar que, em quase todo o período considerado o consumo de água no bairro Faber II foi superior ao consumo medido no bairro Douradinho.

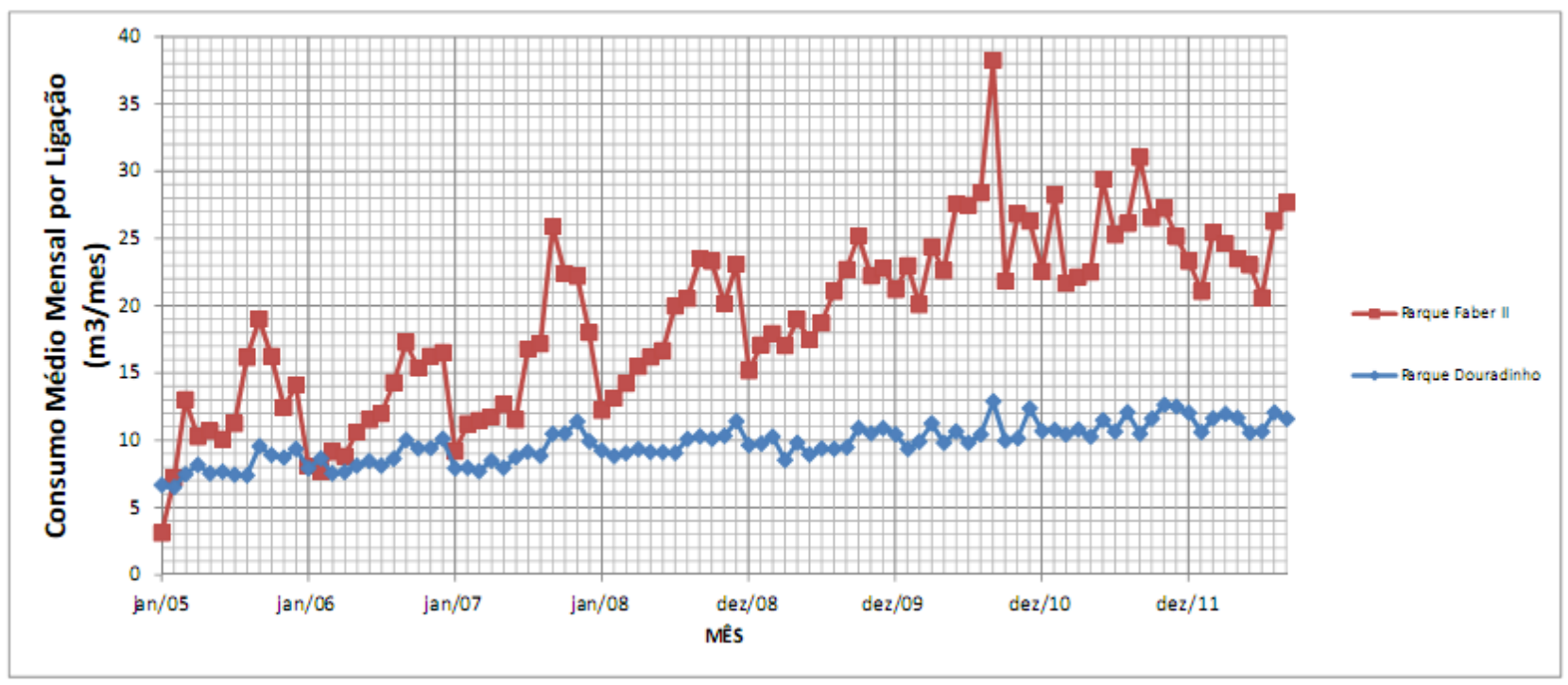

Figura 3: Distribuição dos consumos médios mensais efetivos por ligação dos loteamentos Douradinho e Faber II

Fonte: SAAE-São Carlos (2012).

Esse comportamento, associado às informações apresentadas na Tabela 2, principalmente sobre a taxa de ocupação dos empreendimentos, permitiu inferir que o consumo de água do loteamento Faber II, durante o período de 2005 e 2007 deu-se muito 

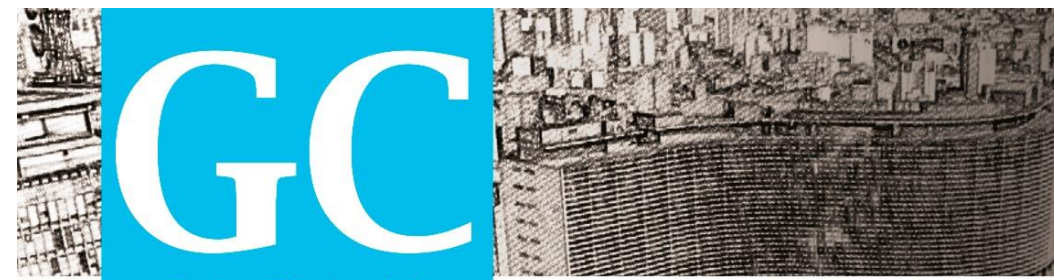

Revista Nacional de

Gerenciamento de Cidades

pelo processo construtivo empregado para a implantação das residências. Para esse período, enquanto a taxa de ocupação do Loteamento Douradinho variou de $45 \%$ a $69 \%$, a taxa de ocupação do loteamento Faber II variou de $17 \%$ a $46 \%$.

Tabela 2: Taxa de ocupação dos bairros Douradinho e Faber II a partir das ligações ativas de água

\begin{tabular}{|c|c|c|c|c|c|c|c|c|c|}
\hline & & 2005 & 2006 & 2007 & 2008 & 2009 & 2010 & 2011 & 2012 \\
\hline \multirow{2}{*}{ 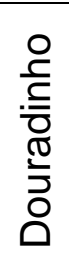 } & $\begin{array}{c}\text { Ligações } \\
\text { Ativas de } \\
\text { Água }\end{array}$ & 579 & 738 & 901 & 1012 & 1094 & 1160 & 1193 & 1206 \\
\hline & $\begin{array}{c}\text { Taxa de } \\
\text { Ocupação }\end{array}$ & $45 \%$ & $57 \%$ & $69 \%$ & $78 \%$ & $84 \%$ & $89 \%$ & $92 \%$ & $93 \%$ \\
\hline \multirow{2}{*}{ 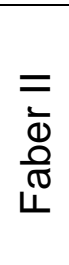 } & $\begin{array}{c}\text { Ligações } \\
\text { Ativas de } \\
\text { Água }\end{array}$ & 23 & 49 & 64 & 83 & 102 & 119 & 123 & 128 \\
\hline & $\begin{array}{l}\text { Taxa de } \\
\text { Ocupação }\end{array}$ & $17 \%$ & $36 \%$ & $46 \%$ & $60 \%$ & $74 \%$ & $86 \%$ & $89 \%$ & $93 \%$ \\
\hline
\end{tabular}

Fonte: SAAE - São Carlos (2012)

Considerando o volume médio efetivo mensal por ligação e o número de ligações ativas de água para o período de 2005 a 2012, conforme mostrado na Tabela 3, o consumo médio mensal por ligação para o Loteamento Douradinho variou de 9,54 a de $12,89 \mathrm{~m}^{3} / \mathrm{mês} /$ ligação, enquanto que para o loteamento Faber II variou de 11,95 a 25,64 $\mathrm{m}^{3} /$ mês/ligação.

Ao se verificar os maiores consumos por ligação para o período analisado, observou-se que o valor máximo obtido para o loteamento Douradinho foi de 12,89 $\mathrm{m}^{3} /$ mês/ligação, enquanto que para o loteamento Faber II, o valor máximo obtido foi de $38,24 \mathrm{~m}^{3} /$ mês/ligação.

Assim, conforme expresso pela Equação (03) obteve-se os valores do coeficiente de dia de maior consumo para os loteamentos Douradinho e Faber II para cada um dos anos analisados, conforme apresentado na Tabela 3.

Para o loteamento Douradinho, os valores de $\mathrm{K}_{1}$ variaram de 1,20 a 1,06, enquanto que para o loteamento Faber II, os valores obtidos para o coeficiente $K_{1}$ variaram de 1,64 

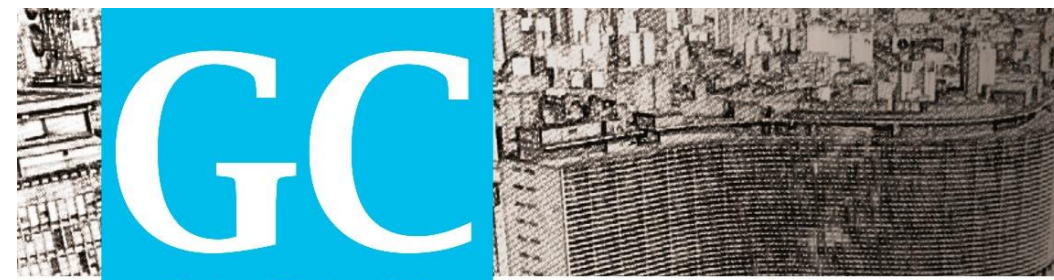

Revista Nacional de

Gerenciamento de Cidades

a 1,15. Segundo a NBR 12.211/1992, o período mínimo a ser analisado é de 5 anos, tomando-se o máximo valor obtido como referência.

Tabela 3: Variação dos coeficientes do dia de maior consumo (K1) para os Loteamentos Douradinho e Faber II

\begin{tabular}{|c|c|c|c|c|c|c|c|c|c|}
\hline \multirow{2}{*}{ Loteamento } & \multirow{2}{*}{ Parâmetro } & \multicolumn{8}{|c|}{ Ano } \\
\hline & & 2005 & 2006 & 2007 & 2008 & 2009 & 2010 & 2011 & 2012 \\
\hline \multirow{3}{*}{ Douradinho } & $\begin{array}{l}\text { Volume médio } \\
\text { mensal por } \\
\text { ligação }\left(\mathrm{m}^{3} / \mathrm{lig}\right)\end{array}$ & 7,94 & 8,66 & 9,07 & 9,65 & 9,78 & 10,58 & 11,19 & 11,41 \\
\hline & $\begin{array}{l}\text { Volume máximo } \\
\text { mensal } \\
\text { observado por } \\
\text { ligação } \\
\left(\mathrm{m}^{3} / \text { lig) }\right.\end{array}$ & 9,54 & 10,10 & 11,39 & 11,40 & 10,91 & 12,89 & 12,64 & 12,05 \\
\hline & $\mathrm{K}_{1}$ & 1,20 & 1,17 & 1,26 & 1,18 & 1,12 & 1,22 & 1,13 & 1,06 \\
\hline \multirow{3}{*}{ Faber II } & $\begin{array}{l}\text { Volume médio } \\
\text { mensal por } \\
\text { ligação }\left(\mathrm{m}^{3} / \mathrm{lig}\right)\end{array}$ & 11,95 & 12,28 & 15,84 & 18,19 & 19,69 & 25,64 & 25,64 & 23,93 \\
\hline & $\begin{array}{c}\text { Volume máximo } \\
\text { mensal } \\
\text { observado por } \\
\text { ligação } \\
\left(\mathrm{m}^{3} / \text { lig) }\right.\end{array}$ & 19,00 & 17,25 & 25,90 & 23,50 & 25,18 & 38,24 & 31,02 & 27,63 \\
\hline & $\mathrm{K}_{1}$ & 1,59 & 1,40 & 1,64 & 1,29 & 1,28 & 1,49 & 1,21 & 1,15 \\
\hline
\end{tabular}

Da análise da Tabela 2, pode-se observar que praticamente, a partir do ano de 2010, as taxas de ocupação de ambos os loteamentos igualaram-se, sendo $89 \%$ de ocupação para o loteamento Douradinho e $86 \%$ para o loteamento Faber II.

Comparando os valores obtidos e apresentados na Tabela 2 e Tabela 3 pode-se verificar que, de maneira geral, o coeficiente do dia de maior consumo $\left(\mathrm{K}_{1}\right)$, para ambos os casos, decaiu a medida que a taxa de ocupação aumentou. Da mesma maneira, é possível observar que é a partir do ano de 2010 que o consumo de água do Loteamento Faber II adquire certa estabilidade, estando os valores médios mensais por ligação da ordem de 25,64 m³/mês.ligação, conforme pode ser observado na Tabela 2.

As Tabelas 4 e 5 apresentam, entre outros, algumas das características socioeconômicas dos setores censitários, obtidos pelo IBGE (2011), e que abrangem as áreas pesquisadas. 

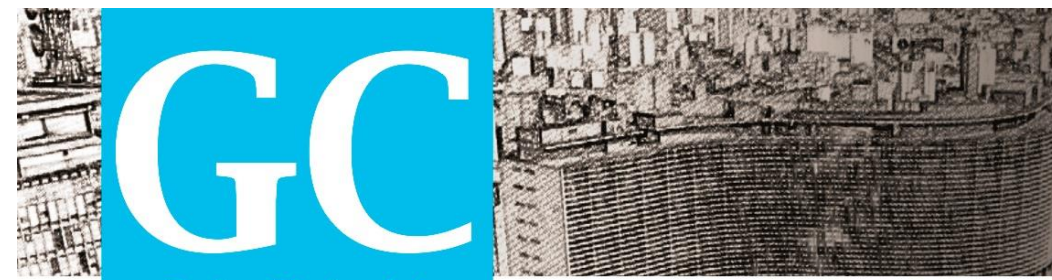

Revista Nacional de

Gerenciamento de Cidades

Tabela 4: Densidade habitacional e número de habitantes nos setores censitários e no loteamento Douradinho

\begin{tabular}{|l|c|c|c|c|c|c|c|}
\hline $\begin{array}{c}\text { Código do Setor } \\
\text { Censitário* }\end{array}$ & $\begin{array}{c}\text { Área do } \\
\text { Setor } \\
\text { Censitário } \\
\left(\mathrm{km}^{2}\right)^{*}\end{array}$ & $\begin{array}{c}\text { Número de } \\
\text { Habitantes } \\
\text { do Setor* }\end{array}$ & $\begin{array}{c}\text { Renda Média } \\
\text { Domiciliar } \\
\text { Mensal* } \\
(\mathrm{R} \$ / \text { domicílio/ } \\
\text { mês })\end{array}$ & $\begin{array}{c}\text { Área do } \\
\text { Setor } \\
\text { Ocupada } \\
\text { em 2010 } \\
\left(\mathrm{km}^{2}\right)\end{array}$ & $\begin{array}{c}\text { Densidade } \\
\text { demográfica } \\
\mathrm{em} \mathrm{2010} \\
\left(\mathrm{hab} / \mathrm{km}^{2}\right)\end{array}$ & $\begin{array}{c}\text { Área do } \\
\text { Empreendi- } \\
\text { mento } \\
\left(\mathrm{km}^{2}\right)\end{array}$ & $\begin{array}{c}\text { Número de } \\
\text { Habitantes do } \\
\text { Empreen- } \\
\text { dimento }\end{array}$ \\
\hline 354890620000029 & 1,97809 & 971 & 2205,10 & 1,97809 & 490,9 & 1,97809 & 971 \\
\hline 354890620000030 & 0,88955 & 1010 & 2403,70 & 0,88955 & 1135,4 & 0,88955 & 1010 \\
\hline 354890620000031 & 1,17621 & 980 & 2005,40 & 1,17621 & 833,2 & 1,17621 & 980 \\
\hline$\Sigma$ & $\mathbf{4 , 0 4 3 8 5}$ & $\mathbf{2 9 6 1}$ & & $\mathbf{4 , 0 4 3 8 5}$ & $\mathbf{7 3 2 , 2}$ & $\mathbf{4 , 0 4 3 8 5}$ & $\mathbf{2 9 6 1}$ \\
\hline
\end{tabular}

Nota: * IBGE (2011)

Tabela 5: Densidade habitacional e número de habitantes no setor censitário e no loteamento Faber II

\begin{tabular}{|c|c|c|c|c|c|c|c|}
\hline $\begin{array}{c}\text { Código do Setor } \\
\text { Censitário* }\end{array}$ & $\begin{array}{c}\text { Área do } \\
\text { Setor } \\
\text { Censitário } \\
\left(\mathrm{km}^{2}\right)^{*}\end{array}$ & $\begin{array}{c}\text { Número de } \\
\text { Habitantes } \\
\text { do Setor* }\end{array}$ & $\begin{array}{c}\text { Renda Média } \\
\text { Domiciliar } \\
\text { Mensal* } \\
(\mathrm{R} \$ \text { /domicílio/ } \\
\text { mês })\end{array}$ & $\begin{array}{c}\text { Área do } \\
\text { Setor } \\
\text { Ocupada } \\
\text { em 2010 } \\
\left(\mathrm{km}^{2}\right)\end{array}$ & $\begin{array}{c}\text { Densidade } \\
\text { demográfica } \\
\text { em 2010 } \\
\left(\mathrm{hab} / \mathrm{km}^{2}\right)\end{array}$ & $\begin{array}{c}\text { Área do } \\
\text { Empreendi- } \\
\text { mento } \\
\left(\mathrm{km}^{2}\right)\end{array}$ & $\begin{array}{c}\text { Número de } \\
\text { Habitantes do } \\
\text { Empreen- } \\
\text { dimento }\end{array}$ \\
\hline 354890620000029 & 5,86778 & 323 & & 1,6508619 & 195,7 & 1,6215899 & 317 \\
\hline
\end{tabular}

Nota: * IBGE (2011)

A partir das populações estimadas para os loteamentos Douradinho e Faber II para o ano de 2010, ano que ocorreu o censo (ver Tabela 4 e

Tabela 5) e comparando com o número de ligações ativas nesses dois loteamentos para o ano de 2010 (ver Tabela 2) determinou-se o número médio de habitantes por ligação. Para o loteamento Douradinho resultou em 2,55 hab/ligação, enquanto que para o loteamento Faber II o resultado foi de 2,66 hab/ligação.

Com os valores do consumo médio efetivo por ligação para o ano de 2010 (Tabela 3) e a densidade habitacional por ligação para o ano de 2010, para cada empreendimento (Tabelas 4 e 5), obteve-se os consumos médios percapita efetivo $\left(q_{e}\right)$ de água para os loteamentos Douradinho e Faber II, que foram 138,3 L/hab.dia e 321,3 L/hab.dia, conforme apresentado na Tabela 6. 
Revista Nacional de

Gerenciamento de Cidades

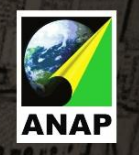

Tabela 6:Consumo médio percapita efetivo de água $\left(\mathrm{q}_{\mathrm{e}}\right)$ e renda média domiciliar mensal para os loteamentos Douradinho e Faber II

\begin{tabular}{|c|c|c|c|c|c|c|}
\hline Loteamento & $\begin{array}{c}\text { Número de } \\
\text { ligações } \\
\text { ativas em } \\
2010\end{array}$ & $\begin{array}{c}\text { Número de } \\
\text { habitantes } \\
\text { em 2010 }\end{array}$ & $\begin{array}{c}\text { Número de } \\
\text { habitantes } \\
\text { por Ligação }\end{array}$ & $\begin{array}{c}\text { Volume médio } \\
\text { mensal por } \\
\text { ligação em 2010 } \\
\text { (m/lig/mês) }\end{array}$ & $\begin{array}{c}\text { Consumo médio } \\
\text { de água } \\
\text { percapita } \\
\text { efetivo } \\
\text { (L/hab.dia) }\end{array}$ & $\begin{array}{c}\text { Renda média } \\
\text { domiciliar mensal } \\
\text { (R\$/domićlio/mês) }\end{array}$ \\
\hline Douradinho & 1160 & 2961 & 2,55 & 10,58 & 138,3 & 2206,75 \\
\hline Faber II & 119 & 317 & 2,66 & 25,64 & 321,3 & 9448,90 \\
\hline
\end{tabular}

Ao analisar os dados da Tabela 6, é possível observar que, embora a densidade habitacional por ligação de água dos dois empreendimentos sejam praticamente a mesma, o consumo médio percapita efetivo de água diferem acentuadamente entre si, uma vez que apresentam diferença da ordem de $232 \%$. Essa diferença no consumo de água pode estar relacionada, entre outros aspectos, a renda média domiciliar mensal, cuja diferença foi da ordem de $428 \%$ entre si.

De modo geral, parece que, enquanto o consumo percapita de água varia segundo a renda percapita da população ou o rendimento domiciliar conforme apontado por Dias, Martinez e Libânio (2010), e/ou pela área construída, a variação sazonal proporcionada por $\mathrm{K}_{1}$ parece relacionar-se com as condições climáticas.

Pela falta de informação sobre a perda física nos sistemas de distribuição de água para os dois empreendimentos, não foi possível determinar o consumo percapita de água. No entanto, ao adotar-se o índice de perda de $20 \%$, conforme sugerido por Tsutiya (2006), o consumo percapita de água (q) dos loteamentos Douradinho e Faber II, resultariam em 172,9 L/hab.dia e 401,6 L/hab.dia, respectivamente.

Comparando-se esses valores com a média nacional para o ano de 2010, que foi de 162 L/hab.dia (SNIS, 2011), observa-se que ambos os empreendimentos estiveram com seus consumos acima da média nacional. Porém, comparando-se os valores de consumo obtidos com o consumo médio para a cidade de São Carlos, no ano de 2010, cujo resultado foi de 189,1 L/hab.dia (SNIS, 2011), é possível observar que o bairro Douradinho apresentou consumo médio mensal dessa mesma ordem de grandeza (172,9 L/hab.dia), enquanto que para o bairro Faber II apresentou consumo médio de 401,6 L/hab.dia, bem acima da média municipal. 


\section{CONCLUSÃO}

- Os consumos médios efetivos por ligação de água para os bairros Douradinho e Faber Il foram de $9,73 \mathrm{~m}^{3} / \mathrm{mês} /$ ligação e $18,99 \mathrm{~m} / \mathrm{mês} /$ ligação, respectivamente.

- Os consumos médios efetivos percapita de água $\left(q_{e}\right)$ para os bairros Douradinho e Faber II foram de 138,3 L/hab.dia e 321,3 L/hab.dia, respectivamente.

- Os consumos médios percapita $(q)$ esperados para os bairros Douradinho e Faber II foram de 172,9 L/hab.dia e 401,6 L/hab.dia, respectivamente, considerando-se perda de $20 \%$ no sistema de distribuição de água.

- Os maiores coeficiente do dia de maior consumo $\left(K_{1}\right)$ obtidos para os bairros Douradinho e Faber II, após análise de conjunto de dados de 5 anos, foram de 1,20 e 1,64 , respectivamente.

- Observou-se correlação entre o consumo de água percapita efetivo e a renda média domiciliar mensal. Enquanto que o consumo médio percapita $\left(q_{e}\right)$ do bairro Douradinho era de $138,3 \mathrm{~L} /$ hab.dia e a renda média domiciliar mensal era de $\mathrm{R} \$ 2.206,75$, no bairro Faber II o consumo médio percapita $\left(q_{e}\right)$ era de 321,3 L/hab.dia e a renda média domiciliar mensal era de $\mathrm{R} \$ 9.448,90$.

\section{AGRADECIMENTOS}

Os autores agradem ao SAAE - São Carlos pela disponibilização dos dados de micromedição utilizados neste trabalho, bem como a CAPES pela bolsa de Iniciação Científica concedida.

\section{REFERÊNCIAS}

ABNT. NB-587: Estudos de concepção de sistemas públicos de abastecimento de água. Rio de Janeiro, 1977. (Cancelada) 
Revista Nacional de

Gerenciamento de Cidades

ABNT. NBR 12.211: Estudos de Concepção de Sistemas Públicos de Abastecimento de Água. Rio de Janeiro, 1992. 14p.

ANA - Agência Nacional de Águas. Pró-Água Nacional: Manual Operativo. Vol II. Brasilia, 2008. $165 \mathrm{p}$.

DIAS, M.D.; MARTINEZ, C.B.; LIBÂNIO, M. Avaliação do Impacto da Variação da Renda no Consumo Domiciliar de Água. Eng. Sanit. Ambient. V.15, n.2. p.155-166. 2010.

IBGE. Base de Informações do Censo Demográfico 2010: Resultados do Universo por setor censitário. Rio de Janeiro, 2011. 201p.

SAAE - Serviço Autônomo de Água e Esgoto de São Carlos. Relatório de micromedição Bairros Douradinho e Faber II. São Carlos, 2012. 40p.

SÃO CARLOS. LEI № 13.691 de 25 de Novembro de 2005. Institui o Plano Diretor do Município de São Carlos e dá outras providências. São Carlos, 2005. 69p+Anexos.

SNIS - Sistema Nacional de Informações sobre Saneamento: diagnóstico dos serviços de água e esgotos - 2007. (2008). Brasília, MCIDADES. Disponível em:

http://www.snis.gov.br/PaginaCarrega.php?EWRErterterTERTer=78

SNIS - Sistema Nacional de Informações sobre Saneamento: diagnóstico dos serviços de água e esgotos - 2008. (2009). Brasília, MCIDADES. Disponível em:

http://www.snis.gov.br/PaginaCarrega.php?EWRErterterTERTer=85

SNIS - Sistema Nacional de Informações sobre Saneamento: diagnóstico dos serviços de água e esgotos - 2009. (2010). Brasília, MCIDADES. Disponível em:

http://www.snis.gov.br/PaginaCarrega.php?EWRErterterTERTer=89

SNIS - Sistema Nacional de Informações sobre Saneamento: diagnóstico dos serviços de água e esgotos - 2010. (2011). Brasília, MCIDADES. Disponível em:

http://www.snis.gov.br/PaginaCarrega.php?EWRErterterTERTer=95

SNIS - Sistema Nacional de Informações sobre Saneamento: diagnóstico dos serviços de água e esgotos - 2011. (2012). Brasília, MCIDADES. Disponível em:

http://www.snis.gov.br/PaginaCarrega.php?EWRErterterTERTer=101

TSUTIYA, M.T. Abastecimento de água. 1ํㅡdição, São Paulo, DHS/POLI - USP. 2006. 643p 